\title{
Tecnologia Educacional
}

\section{Sampaio, M. N.; Leite, L. S. Alfabetização Tecnológica do Professor. 2 ed. Petrópolis, RJ: Vozes, 2001.}

\begin{abstract}
A ação da imagem sobre as pessoas é um tema que vem sendo observado desde meados da década de 1970, merecendo especial atenção por parte dos educadores. Hoje, a alfabetização tecnológica é condição básica para a sobrevivência do professor.

Sem desprezar a importância das aulas expositivas e da escrita como uma das formas mais primitivas de registro, não há como negar a necessidade de se pensar em um tipo de alfabetização audiovisual, uma vez que, nos dias atuais, há uma grande variedade de tecnologia à qual os alunos estão expostos, sendo por ela influenciados e fazendo parte do seu dia-a-dia.

Para inserir-se no contexto e com a responsabilidade de formar cidadãos capazes de conviver harmoniosamente com os avanços técnicos, o educador precisa pensar em uma escola e em novos métodos pedagógicos que atendam a essa necessidade.

Dado que a tecnologia alcança tanto a pobres quanto a ricos, deve o professor buscar subsídios para que ela não se transforme em um elemento de segregação social. Para tanto, a transformação deve começar por ele próprio, buscando inteirar-se sobre os novos padrões impostos pela era da cibernética de maneira que ela possa estender-se a ambas as clientelas.

Como a escola não pode ficar à margem do processo e sendo o professor a figura que mais representa a educação, naturalmente ele precisa atualizar-se constantemente, buscando adequar-se ao novo perfil do professor na sociedade tecnológica, proporcionando aos seus alunos uma formação crítica e cidadã que lhes possibilite dominar, compreender e utilizar esses avanços em seu benefício, em benefício de suas famílias e de toda a sociedade.

Nascida, no Brasil, na década de 1960, a preocupação de aproximar a educação das demandas do mercado chegou com o tecnicismo de Taylor, que buscava inserir o ambiente escolar nas organizações empresariais, o que fez brotar, como corolário, uma nova pedagogia, voltada a fazer com que o estudante pudesse integrar-se de forma ativa na sociedade.
\end{abstract}

Atualmente, em função da pujança do sistema capitalista, o avanço tecnológico tem sido motivo de abalo, até certo ponto, entre as nações, uma vez que as que detêm maior domínio científico acabam por ditar as regras, o que faz presumir que, se esse poder pertencer apenas à minoria, há um sério risco de atentado à democracia.

Isso, naturalmente, aumenta ainda mais a responsabilidade dos pedagogos, que devem partir em busca de mudanças na área da educação visando implementar as necessárias transformações para que todos os homens, ou pelo menos a maioria deles, possam tornar-se sujeitos ativos da tecnologia, diminuindo, assim, a possibilidade de um colapso mundial.

Tendo a Segunda Grande Guerra como o marco inicial do avanço tecnológico, quando os Estados em conflito aprimoravam os seus conhecimentos visando destruir o inimigo, curiosamente essa mesma tecnologia foi a grande responsável para a reconstrução dos países no pós-guerra.

As invenções passaram, mutatis mutandis, para o campo dos negócios, gerando uma verdadeira revolução na indústria, com o surgimento de novos e sofisticados produtos em todos os segmentos, o que culminou com a expansão do capitalismo. Como conseqüência nasceu a globalização, os hábitos de consumo foram homogeneizados e dissolvidos os limites dos territórios nacionais.

Aos educadores cabe, agora, a difícil tarefa de repensar o mundo novo, atentos às suas peculiares características, tendo como grande desafio a necessidade de ajudar na formação de cidadãos com consciência crítica, atuantes e de visão supranacional, para viver em um globo já sem as suas antigas fronteiras, onde a comunicação se dá por fax, internet, satélite etc, entrelaçando as informações simultaneamente em toda a sua extensão.

As transformações, que agora se processam em velocidade espantosa, têm a mídia como a grande aliada, totalmente sob o controle das elites dominantes, 
exercendo poderosa influência sobre toda a sociedade, especialmente sobre os jovens estudantes que, fascinados pelas suas linguagens e mensagens, tornamse mais adeptos das imagens do que da escrita, criando a cultura do audiovisual em detrimento da leitura.

As tantas informações e imagens mudaram a figura da família e, como numa progressão geométrica, influenciam as crianças, mudam seus hábitos e atitudes, interferem nas relações com a escola e, novamente, o professor é desafiado a encontrar soluções.

Nessa nova realidade já não cabem aulas apenas expositivas, porque o que interessa não é mais o volume de informações, mas o que fazer com tantas delas. A escola, agora, tem de criar condições para que o aluno tenha acesso e meios para analisá-las, numa relação muito próxima com a ciência e a tecnologia, com o compromisso de instrumentalizá-lo para encontrar soluções para os acontecimentos do seu cotidiano. Cabelhe, ainda, lutar para diminuir barreiras sociais, socializar o conhecimento e superar as desigualdades.

Em virtude disso, a alfabetização tecnológica do professor torna-se irrefutável, assumindo um caráter de provisoriedade porque não mais poderá dizer-se acabada, uma vez que deve estar em constante renovação, no ritmo dos avanços tecnológicos.

Sem poder eximir-se de levar a tecnologia para a sala de aula, o profissional do magistério há de encontrar outras formas para educar porque "é necessário desenvolver também um nova pedagogia, pois não adianta 'empregar' uma nova tecnologia para aplicar uma velha pedagogia"” (p. 66).

Paralelamente a isso e se é inegável que o momento requer novas maneiras de ensinar, é necessário que essa visão chegue também aos centros de formação de professores, conscientizando os universitários de que não mais poderão utilizar a expressão "dia da formatura”, uma vez que esta estará sempre por vir.

Dadas as diferenças sociais que, embora se lutem para amenizar elas jamais se extinguirão, o professor não pode desistir do uso da tecnologia sob o pretexto de estar trabalhando com uma comunidade pobre porque a tecnologia não está restrita à microeletrônica ou à grande mídia.

Tudo o que cerca o aluno, que vai de rádio a vídeocassete, de microondas a televisão, deve ser utilizado. A esses produtos, como se sabe, todas as camadas sociais hoje têm acesso em maior ou menor escala. "Se as tecnologias fazem parte da vida do aluno fora da escola (...) elas devem fazer parte também de sua vida dentro da escola" (p. 73), o que deverá colaborar para afastá-lo de uma visão puramente empírica e conduzi-lo a um pensamento de mundo mais elaborado.

De forma reduzida, a alfabetização tecnológica do professor pode ser entendida como "o conceito que envolve o domínio contínuo e crescente das tecnologias que estão na escola e na sociedade, mediante o relacionamento crítico com elas" (p. 75).

A presente obra é composta de quatro capítulos e finalizada pelo que as autoras chamaram de "algumas últimas idéias".

Seu objetivo é promover uma discussão sobre como o professor do ensino fundamental e médio deve utilizar a tecnologia como ferramenta de trabalho, abordando, também, questões sobre a formação dos novos profissionais do magistério para atuar numa sociedade tecnológica.

Do ponto de vista crítico, afora o conteúdo, ao qual acabamos de nos referir, pode-se afirmar que se trata de uma produção muito bem elaborada.

No primeiro capítulo, as autoras falaram de "Professor e Tecnologia", indagando: Professor, por que alfabetização tecnológica? Ao segundo elas chamaram de "Sociedade e Tecnologia" e discorreram sobre a sociedade atual. O terceiro capítulo é o que dá nome ao livro, qual seja “Alfabetização Tecnológica do Professor" e lá argumentaram sobre o seu porquê.

Esses três primeiros capítulos tratam de temas diferentes, mas articulam-se perfeitamente e, não obstante guardarem a sua independência, não se constituem em unidades autônomas.

O quarto e último capítulo as autoras reservaram para detalhar o trabalho de campo realizado, o qual serviu para a sustentação e fundamentação do livro. Finalizando, vêm “algumas últimas idéias", como num fechamento da produção.

Em cada um dos três capítulos iniciais as autoras introduzem a idéia, argumentam-na e concluem com muita propriedade, fato que particulariza o livro e conduz o leitor à reflexão, até pela novidade que o tema representa, sobe o qual ninguém havia ainda descido a tantos detalhes.

A obra é muito bem elaborada, pautada pela colocação sempre oportuna dos vocábulos, articulada a partir de algumas expressões técnicas, mas que nem por isso oferecem dificuldade para o seu entendimento. As idéias são claras e demonstram, pela qualidade do texto, que o trabalho é fruto de extensa pesquisa, fato que também se nota pela quantidade e qualidade das referências bibliográficas citadas. 


\section{Resenhas}

É provável que mesmo os críticos mais severos terão poucos argumentos para contradizer os sábios caminhos que as autoras trilharam para falar sobre a "alfabetização tecnológica do professor”, uma vez que o fizeram com desenvoltura, de maneira eclética e desapaixonada.

Assim, é digna de todos os elogios a obra em estudo. Quanto à revisão textual, nenhuma incorreção significativa foi notada.

Há, não se pode negar, uma ou outra colocação extemporânea de vírgula. Contudo, dentro do moderno entendimento de que esta sinalização está deixando de ser regra para incorporar-se à subjetividade de cada autor, não há de se lhe atribuir demasiada importância até porque a obra, no seu contexto geral, apresenta-se de forma que absorve integralmente esta contemporaneidade da gramática.

Relativamente ao conteúdo, inegavelmente é primoroso. Desenvolvendo o tema de forma que prende a atenção do leitor, oferecendo um estilo suave e agra- dável, as autoras esbanjam conhecimento, competência técnica e literária.

O leitor adepto a pormenores poderá acusar que, em certos momentos, há algumas colocações repetitivas, quando as autoras se referem, mais de uma vez, à necessidade de "formação de cidadãos críticos", mas a sequiência da leitura logo afasta ou contemporiza esse sentimento.

A proposta é convincente, translúcida, com argumentos bem fundamentados e sua linha encanta por não se mostrar tendenciosa nem com arrogos de sectarismo. É realmente, repita-se, uma obra primorosa, recomendável não somente aos profissionais da educação, mas a todos aqueles que queiram buscar informações atualizadas sobre o novo perfil do professor na sociedade tecnológica.

\section{Luiz Costa}

Universidade São Francisco - Itatiba/SP 